\title{
Justification of the algorithm of personnel selection for the maintenance of automated technological processes in agricultural production
}

\author{
V.V. Kuzmenko ${ }^{1, *}$, A.M. Troshkov², I.P. Kuzmenko ${ }^{2}$, E.U. Karakaeva ${ }^{3}$, and Kh.M. \\ Tambieva ${ }^{4}$ \\ ${ }^{1}$ North-Caucasian Federal University, Stavropol, Russia \\ ${ }^{2}$ Stavropol State Agrarian University, Stavropol, Russia \\ ${ }^{3}$ North-Caucasian State Humanitarian and Economic Academy, Cherkessk, Russia \\ ${ }^{4}$ Karachay-Cherkess State University n.a. U.D. Aliyev, Cherkessk, Russia
}

\begin{abstract}
The current stage of strengthening and development of market relations is characterized by increased competition in all spheres of the economy, including agriculture. To strengthen competitive positions, agricultural producers use high-tech equipment complete with elements of automation and microprocessor technology. Only highly qualified specialists with knowledge in the field of both information technology and agriculture can maintain such equipment and manage its operation. The article presents the justification for the structure and content of the algorithm for performing the professional selection of candidates for specialists in the maintenance of high-tech equipment containing elements and mechanisms of microprocessor technology. A description of a specialized digital platform is given that allows for a formalized assessment of the candidate's compliance with the requirements for a number of characteristics: qualification coefficient, time spent on managing changes in the system, and response time of the specialist to the tasks set. It is noted that according to the results of the presented development, a certificate of state registration of the computer program was obtained.
\end{abstract}

\section{Introduction}

The current stage of strengthening market competition determines the need for constant modernization of technological processes at enterprises and organizations in all sectors of the economy, including agriculture. The newly commissioned equipment is usually equipped with high-tech automatic control devices containing microprocessor elements and mechanisms. Their service requires highly qualified personnel with special competencies in the application of modern information technologies. In the agricultural sector, these

\footnotetext{
* Corresponding author: kuzmenko.v.v@mail.ru
} 
workers must also have some knowledge in the field of crop production, animal husbandry or agricultural products processing.

The selection of specialists for the maintenance of high-tech machinery and equipment in agriculture is not an easy task and is always accompanied by the presence of certain risks: making particular or general selection errors, taking into account subjective factors, presence of unstable connections in the system "man - machine - biological object". This makes it advisable to develop formalized recruitment algorithms for managing automated production lines $[1,3,4,8]$.

The development of a methodology for identification of the employee's compliance with the requirements should be based on well-known mathematical tools that would allow to consider a set of factors: individual and general characteristics of a person, technical parameters of a machine, processes of adapting the employee's professional skills to the requirements of automated production maintenance [2, 5].

The purpose of the research is to develop a formalized algorithm for personnel selection for maintenance of automated process lines containing complex microprocessor elements and devices. Its achievement determines the need to solve a number of interrelated tasks, which include the following:

- identification of the risks of a specialist performing reliable management of technically complex equipment containing elements of microprocessor technology and operating with the use of modern information technologies;

- justification of a rational method of professional selection of personnel capable of reliable management of high-tech equipment in accordance with the rules of its technical operation in the conditions of the agricultural sector of the economy.

\section{Materials and methods}

In solving the formulated problems, general scientific tools of cognition based on the methodology of structural analysis and synthesis, methods of expert assessments, risk analysis, and mathematical modeling were used. In particular, to achieve the research goal, it is necessary to create a model of the corresponding process, design its implementation according to the main stages and functions. A model project is a set of interrelated elements designed to achieve certain goals with a set supply of resources, in a fixed period of time, and with a forecast cost. Since each project has a specific time frame and expected results, there are also uncertainties, considered as risks that may arise under certain conditions and will affect the successful implementation of the project. Risks are characterized by two factors: probability of uncertainty and possible consequences.

The uncertainty analysis is based on a deeper study of what tasks, conditions, or events will affect the successful implementation of the project. This requires project managers to have experience, knowledge of the process essence, and a critical understanding of alternative strategies for achieving the goal.

The risk analysis can be performed by performing qualitative and quantitative assessments. In the first case, a descriptive method is used to form the characteristics of the process, possible outcomes and potential consequences. The second one provides for quantitative measurements, numerical characteristics of the probability of achieving the set goal, which may require significant time and resources for implementation. The level of detail depends on the range of data used and the depth of calculation used to present the results, which will indicate the extent of the impact and the probability of an adverse outcome. By conducting qualitative and quantitative assessments of the uncertainty level, it is possible to identify possible risks of successful project implementation and to form a set of conditions sufficient to achieve the set goals. 
Risk identification is the process of diagnosing a set of factors that can negatively affect the project, which ends with fixing their main characteristics. The result of the risk identification process may be their corresponding register. With the help of an online risk analysis service, we have compiled such a document (Table 1):

Table. 1. Risk register

\begin{tabular}{|c|c|c|c|c|c|c|c|c|c|c|}
\hline No & 竎 & 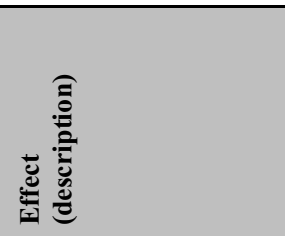 & 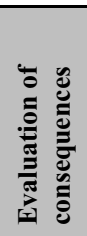 & 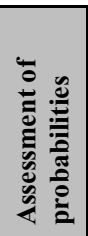 & 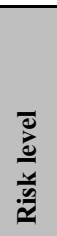 & 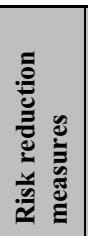 & 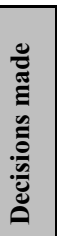 & 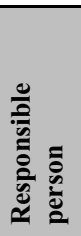 & 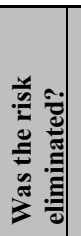 & 这 \\
\hline 1 & Server outage & $\begin{array}{l}\text { Occurrence of } \\
\text { technical malfunctions } \\
\text { in the server, the cause } \\
\text { of which can be both } \\
\text { external and internal } \\
\text { factors }\end{array}$ & 3 & 10 & 30 & & & & & \\
\hline 2 & $\begin{array}{l}\begin{array}{l}\text { Loss of } \\
\text { databases }\end{array} \\
\end{array}$ & $\begin{array}{l}\text { Loss or malfunction of } \\
\text { the database }\end{array}$ & 2 & 8 & 16 & & & & & \\
\hline 3 & $\begin{array}{l}\text { Difficulties in } \\
\text { working with } \\
\text { the site }\end{array}$ & $\begin{array}{l}\text { Lack of understanding } \\
\text { of the functionality of } \\
\text { the resource, as well as } \\
\text { interaction with users }\end{array}$ & 5 & 5 & 25 & & & & & \\
\hline 4 & $\begin{array}{l}\text { Breach of } \\
\text { confidentiality }\end{array}$ & $\begin{array}{l}\text { Breach of data } \\
\text { confidentiality by } \\
\text { organization } \\
\text { employees }\end{array}$ & 4 & 7 & 28 & & & & & \\
\hline 5 & Power outage & $\begin{array}{l}\text { Inoperability of the } \\
\text { resource due to } \\
\text { external factors }\end{array}$ & 4 & 6 & 24 & & & & & \\
\hline 6 & $\begin{array}{l}\text { Loss of } \\
\text { domain }\end{array}$ & $\begin{array}{l}\text { Late payment for a } \\
\text { domain with the } \\
\text { subsequent purchase of } \\
\text { another one }\end{array}$ & 2 & 5 & 10 & & & & & \\
\hline 7 & $\begin{array}{l}\text { Incorrect site } \\
\text { display }\end{array}$ & $\begin{array}{l}\text { Lack of adaptability for } \\
\text { different devices }\end{array}$ & 4 & 3 & 12 & & & & & \\
\hline
\end{tabular}

During the identification process, the list of risk categories may be supplemented with new components, which may lead to an expansion of the hierarchical structure developed at the risk management planning stage.

Figure 1 shows in tabular form the relationship between consequences and probability, which is called a risk map or risk assessment matrix. It can be used to quantify risk using graphical representations. With the numerical values of the uncertainty indicators, the project manager will gain an idea of which risks should be given additional attention.

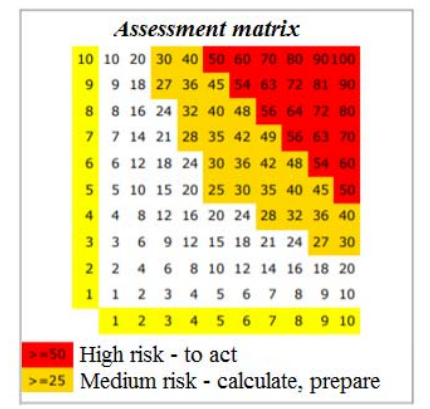

The risk level is obtained by multiplying the estimates of consequences and probability. The high level includes risks with an assessment of over 50 , the average - over 25 .

Fig. 1. Risk assessment matrix 
Based on the data of the presented matrix, it can be concluded that only two values from the generated register are in the zone with an average level of uncertainty, and one is on the border of the average and low. In tabular and graphical forms, the distribution by risk level is shown in Figure 2.

\begin{tabular}{|l|c|c|r|}
\hline \multicolumn{1}{|c|}{ Description } & Risk factor & Risk qty. & \multicolumn{1}{c|}{$\begin{array}{c}\text { Share of risks } \\
\text { of this level }\end{array}$} \\
\hline Low risk $(<=25)$ & 25 & 5 & $71.4 \%$ \\
\hline Medium risk $(<=50)$ & 50 & 2 & $28.6 \%$ \\
\hline High risk $(<=75)$ & 75 & 0 & $0.0 \%$ \\
\hline Extremely high risk $(<=100)$ & 100 & 0 & $0.0 \%$ \\
\hline
\end{tabular}

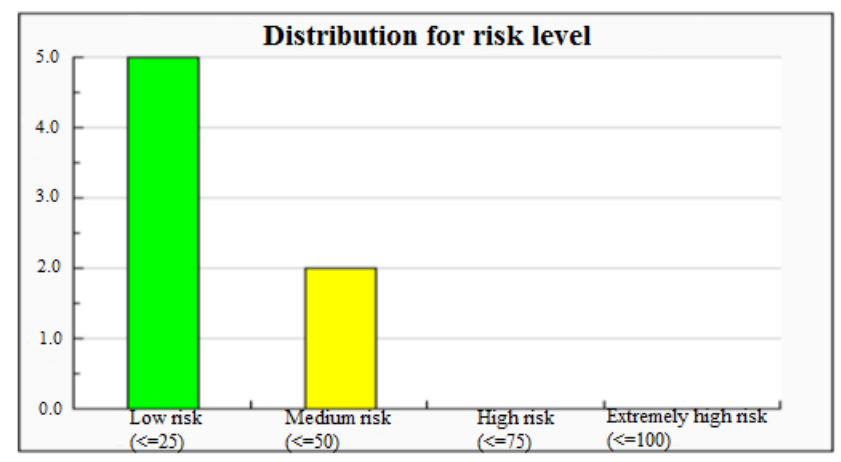

Fig. 2. Distribution by risk level

The results of the presented method for assessing the risks of reliable management of high-tech equipment are the following: reducing the level of uncertainty, making rational decisions on key issues at each stage of the project implementation, as well as promptly diagnosing the risks associated with specific solutions.

The considered risks allow to start designing the program of operational efficiency of a specialist in the maintenance of high-tech equipment containing elements of microprocessor technology. The root cause of any error is an operational failure. Moreover, the same, essentially erroneous actions of the operator (for example, untimely pressing of a button) can lead to errors of five different types, manifested in the malfunction of the equipment, damage to information, disorganization of the staff, incorrect or irregular functioning of the entire system. The noted circumstance requires that when developing a performance model, it is not the process of operational failures occurrence that should be guided, but the consequences of errors should be considered in the models of hardware, information and functional performance [7]. The distribution of staff errors by type can be carried out when analyzing the activities of specific specialists. The available data only approximate this distribution. Statistical data on violations in the equipment operation indicate that about a third of them are not related to equipment failures, but to improper actions of personnel, with violations of the rules of technical means operation.

To manage any processes in the system, the following formula is valid:

$$
\mathrm{T}=t_{f}+t_{r}+t_{l}
$$

where $\mathrm{T}$ is the permissible transience of the process in the system;

$t_{f}-$ the time required to make a change in the functioning of the system elements;

$\mathrm{t}_{\mathrm{r}}$ - reaction time; 
$\mathrm{t}_{1}$ - time of additional restrictions.

If the process speed is such that dangerous situations can occur in the operating time $t$, which is less than $t_{f}+t_{r}$, then, obviously, the operator of the microprocessor technology is not able to reliably control the system. The probability of error-free control $U_{t}$ is 0 . Thus, the basic criterion will be the ratio:

$$
\frac{t}{t_{f}+t_{r}}
$$

The algorithm for implementing the professional selection of personnel performing maintenance of complex equipment containing elements of microprocessor technology should be based on estimates of the probability of error-free control of the system, considering the criterion (2). For this purpose, it is necessary to run the calculation program and enter the following characteristics:

$\mathrm{k}$ - coefficient of specialist qualification;

$\mathrm{t}_{1}$ - time required to manage changes in the system;

$t_{2}$ - response time of the specialist.

The proposed calculation procedure should be carried out sequentially in three stages:

1. Study of the dependence of reliable (error-free) work of a specialist on the level of qualification:

$U_{t}=f(k)$, with $t_{1}=$ const, $t_{2}=$ const .

Limitations: $(k=1-5), t_{1}$ and $t_{2}=$ from 1 to 3 .

2. To study the dependence of the error-free operation of a specialist on $t_{1}$, as the time required to manage changes in the system:

$U_{t}=f\left(t_{1}\right)$ with $k$ and $t_{2}=$ const, $t_{1}=1-5$.

3 . To study the dependence of the error-free specialist operation on the reaction time of a specialist in the maintenance of microprocessor equipment

$U_{t}=f\left(t_{2}\right)$ with $k$ and $t_{1}$ - const, $t_{2}=1-5$.

The proposed software platform contains theoretical materials on the topic of studying the operational efficiency of the specialist in microprocessor technology, an intelligent user interface, a calculation part, etc.

\section{Results and discussion}

The developed computer program is characterized by practical significance and provides the following functions:

- theoretical study of modeling the operational efficiency of an equipment maintenance specialist with elements of microprocessor technology;

- input of initial data for professional selection;

- obtaining the calculation results based on the specified source data and graphical construction of functional dependencies.

- Type of computer: IBM PC - compatible with PC.

- Language: Delphi, Html, AutoPlay, Media Studio 8.

- OS: Windows 98, ME, 2000, XP, W7, Vista.

- Program size: $23.7 \mathrm{MB}$.

Figure 4 shows a visualization of the process of conducting a study of the dependence of the specialist error-free work on the values $1,2,3$. 


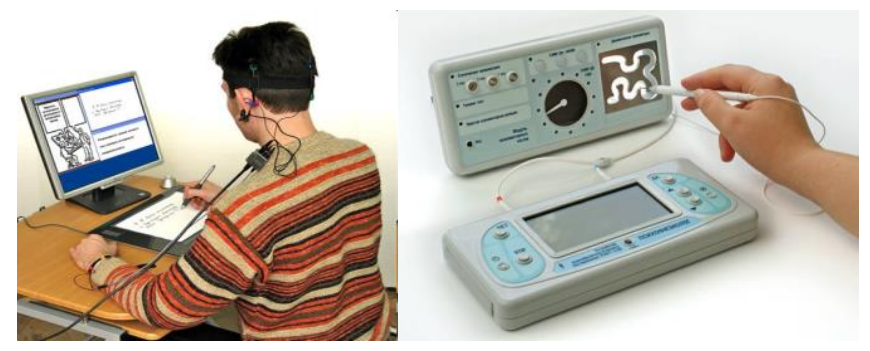

Fig. 3. Visualization of the process of conducting the study of the dependence of the specialist errorfree work

Figure 4 shows the program dialog box during the start of the study.

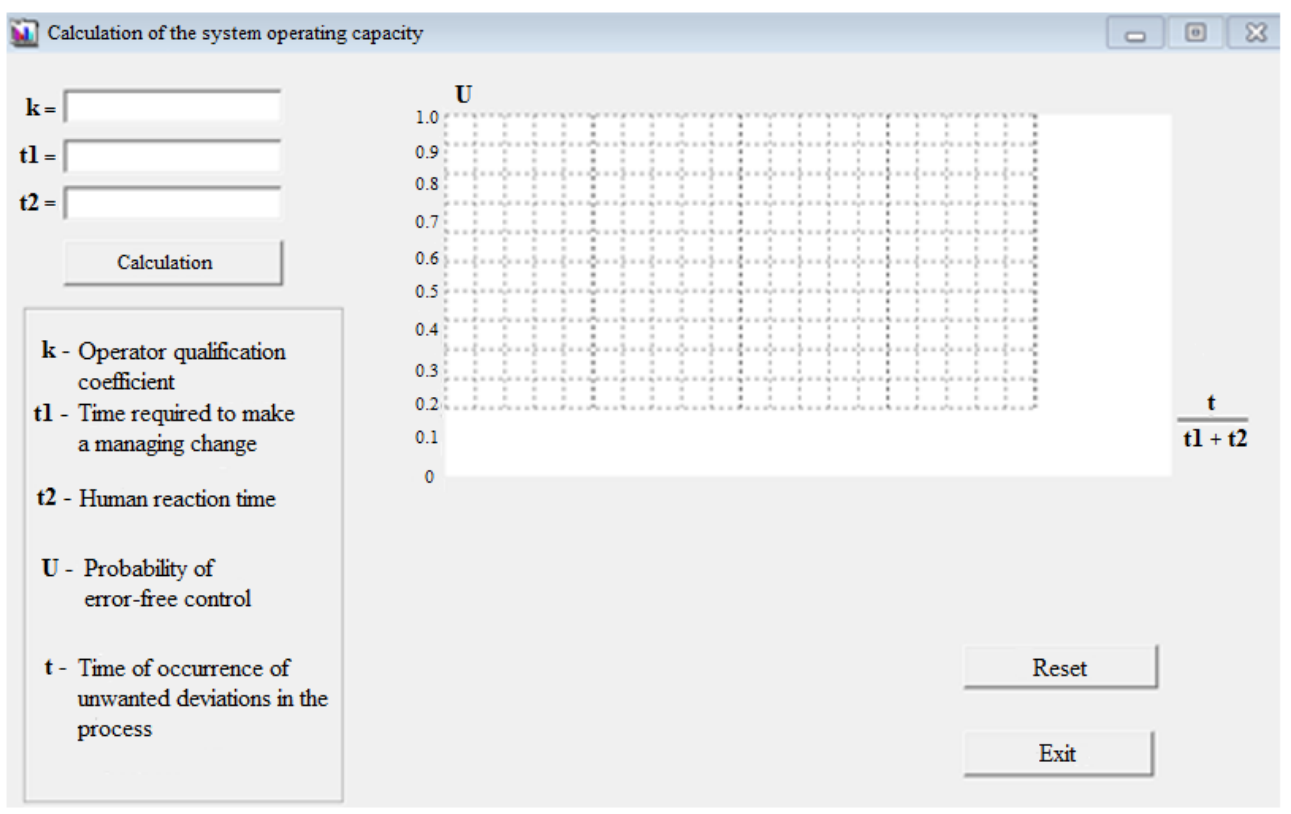

Fig. 4. The program dialog box during the start of the study.

After entering the data and performing the calculations, we obtained the numerical values of professional selection characteristics, which are presented graphically in Figure 5. 


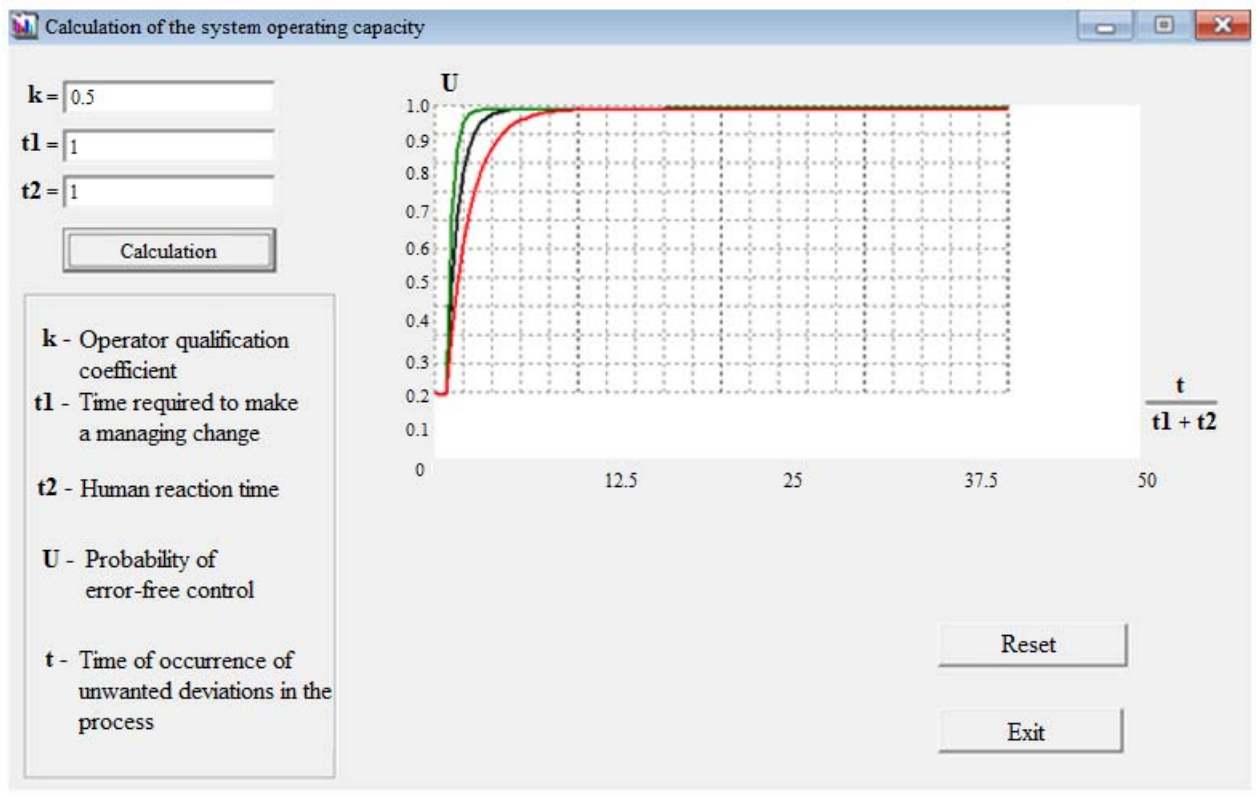

Fig. 5. Graphical results of professional selection implementation.

Based on the graphically presented data, it is possible to analyze the numerical values of high-tech equipment containing elements of microprocessor technology. According to the results of the presented development, on November 11, 2019, a certificate of state registration of the computer program No. 2019664644 was received [6].

\section{Conclusions}

The introduction of a software platform for the automated workplace of the head or specialist of the personnel management service will allow to qualitatively increase the selection of candidates for performing operations for maintenance of the equipment with elements of microprocessor technology, as well as the efficiency of making decisions on the placement of employees in the appropriate positions. The presented software platform has a FIIP state registration and can be implemented in the personnel management system of an agricultural enterprise or an organization of any organizational and legal form and ownership. The application of the results of the study in the production processes of the leading milk processing organizations of the Stavropol Krai allowed to increase the operational efficiency of specialists and reduce by $37.4 \%$ the number of errors made by employees when maintaining high-tech equipment.

\section{References}

1. A.M. Vinogradenko, I.V. Fedorenko, System for monitoring the parameters of technological objects, Utility model patent RU 96676 U1, 10.08.2010, Application No. 2010108576/22 dated 09.03.2010.

2. I.I. Glotova, E.P. Tomilina, I.P. Kuzmenko, Life Science Journal, 11(5), 536-541 (2014) 
3. A. Zhuk, A. Gavrishev, V. Rachkov, I. Kuzmenko, Qualitative Study of Some Communication Systems with Random Signals, 7th Scientific Conference on Information Technologies for Intelligent Decision Making Support (ITIDS 2019)

4. G.V. Kipor, E.V. Kozlov, V.V. Bessonov, S.N. Zaitseva, Medicine of Catastrophes, 1, 35-37 (2012)

5. E.P. Tomilina, I.I. Glotova, I.P. Kuzmenko, Middle East Journal of Scientific Research, 13 (SPLISSUE), 178-182 (2013)

6. A.M. Troshkov, V.P. Gerasimov, V.I. Sapozhnikov, M.A. Troshkov, A.V. Kazakov, The model of the software platform of the information security specialist operational efficiency, Certificate of registration of the computer program RU 2019664644, 11.11.2019. Application No. 2019662993 dated 21.10.2019.

7. A.M. Troshkov, M.A. Troshkov, D.V. Shlaev, I.V. Samoylenko, V.E. Rachkov, A.P. Zhuk, I.P. Kuzmenko, D.N. Rezenkov, Bulletin of the Agroindustrial Complex of Stavropol Krai, 1(25), 57-62 (2017)

8. N.A. Shchegryaev, Lectures on the discipline "Information support of management systems", 326 (Moscow, Kvarsit, 2015) 